\title{
ANALISIS KEBUTUHAN PENGEMBANGAN MODEL-MODEL STUDENT-CENTERED LEARNING UNTUK MENINGKATKAN PENALARAN DAN KARAKTER SISWA SMA
}

\author{
I Wayan Santyasa ${ }^{1}$, I Wayan Sukra Warphala ${ }^{2}$, I Made Tegeh ${ }^{3}$ \\ 1,2,3 Jurusan Teknologi Pembelajaran \\ Program Pascasarjana \\ Universitas Pendidikan Ganesha \\ Singaraja, Indonesia \\ e-mail: santyasa@yahoo.com, yan.sukra@yahoo.co.uk, \\ imadetegehderane@yahoo.com
}

\begin{abstract}
Abstrak
Penelitian ini bertujuan melakukan analisis kebutuhan pengembangan modelmodel Student-Centered Learning (SCL). Penelitian dilakukan dengan metode survey pada 9 (sembilan) kabupaten/kota di Provinsi Bali. Subjek penelitian adalah 27 kepala sekolah, 54 guru, 54 RPP, 54 LKS, dan 362 siswa SMA. Objek yang dikaji adalah tanggapan kepala sekolah dan guru terhadap pengembangan modelmodel SCL, kecenderungan guru menerapkan model-model SCL dalam pembelajaran di sekolah, penalaran siswa, dan karakter siswa. Data dikumpulkan dengan wawancara, angket, observasi, dan tes. Data dianalisis secara deskriptif. Hasil analisis menunjukkan, bahwa (1) kepala sekolah belum melakukan pembinaan pengembangan model-model SCL, sehingga mereka mendukung upaya pengembangan, (2) guru-guru belum mengembangkan dan menggunakan model-model SCL, sehingga mereka mendukung dan menyatakan kesiapan untuk terlibat dalam pengembangan, (3) model-model pembelajaran yang digunakan oleh para guru selama ini belum ada indikasi mengarah pada model-model SCL, (4) penalaran siswa berkategori kurang, dan (5) masih terdapat $40,21 \%$ siswa memiliki karakter yang perlu ditingkatkan kualifikasinya ke arah yang lebih baik. Implikasinya, pengembangan model-model SCL adalah program strategis untuk dilakukan.
\end{abstract}

Kata-kata kunci: Model-model SCL, penalaran siswa, karakter siswa

\begin{abstract}
This research aimed at conducting need assessment about development of Student-Centered Learning (SCL) models. This research used survey method on the 9 (nine) regency/city in Bali Province. The research involved 27 of the school heads, 54 of teachers, 54 of teachers' plan, 54 of student work sheet, 362 of students. The objects of the research were school heads and the teachers responses on the idea of development of the SCL, the trend of the teachers to develop and conduct the SCL models in fascilitating student learning in school. The data were collected by interview, questionaire, observation, and tests. To analyse of the data, the descriptive statistic were used. The resuls of the analyses show
\end{abstract}


that (1) the school heads did not yet to conduct supervission specially in developing the SCL models, so they will support the developmental programm, (2) the teachers did not yet to develop and use the SCL model, so they will support and ready to involve in the developmental programm, (3) there were not an indication that the teachers used the SCL models until now, (4) the students' reasoning was less, and (5) there were still $40.21 \%$ of the students' character qualification need to enhance to become better. The research implication is the development of the SCL models is a strategic programm to be conducted.

Key words: SCL models, students' reasoning, students' character

\section{PENDAHULUAN}

Menurut UU Nomor 20 Tahun 2003 tentang Sistem Pendidikan Nasional, pendidikan nasional bertujuan mengembangkan potensi peserta didik agar menjadi manusia yang beriman dan bertakwa kepada Tuhan Yang Maha Esa, berakhlak mulia, sehat, berilmu, cakap, kreatif, mandiri, dan menjadi warga negara yang demokratis serta bertanggung jawab. Selanjutnya, Peraturan Menteri Pendidikan Nasional Nomor 41 Tahun 2007, mengungkapkan bahwa penyelenggaraan pendidikan melalui pembelajaran adalah sebagai proses pembudayaan dan pemberdayaan peserta didik yang berlangsung sepanjang hayat.

Untuk mendukung proses pembudayaan dan pemberdayaan peserta didik, diperlukan fasilitas yang mampu memberikan keteladanan, membangun motivasi, dan mengembangkan potensi serta kreativitas peserta didik. Hal ini merupakan salah satu implementasi bergesernya paradigma dari teaching menuju learning. Implikasinya, modelmodel pembelajaran tidak tepat lagi jika menganut paham teacher centerred, namun harus bergeser menuju student centered learning. Paradigma student centered learning menunjukkan bahwa pemberdayaan potensi diri siswa melalui langkah-langkah proaktif dalam menggali ilmu pengetahuan menjadi sentra pembelajaran, sedangkan guru hanya menjadi fasilitator bagi siswa.

Paradigma student centered learning yang sudah umum dibicarakan, secara khusus lebih dijelaskan oleh Depdiknas (2009) melalui paradigma pendidikan dan pemberdayaan manusia seutuhnya. Manusia utuh berarti memiliki hak untuk mengaktualisasikan dirinya secara maksimal dalam aspek kecerdasan intelektual, spiritual, sosial, dan kinestetik. Anak tidak lagi dipaksakan untuk menuruti keinginan orang tua, atau guru di sekolah, namun orang tua atau guru hanya sebagai fasilitator membantu anak menemukan bakatnya serta menolongnya agar mampu memaksimalkan potensi yang ada pada dirinya. Di sekolah, Guru tidak hanya memberikan pengajaran yang dibutuhkan, tetapi juga memberi dan menjadi teladan bagi anak untuk mengembangkan kreativitas. Paradigma ini merupakan fondasi pendidikan kreatif agar anak menjadi subyek pembelajar mandiri, bertanggung jawab, kreatif, inovatif. Paradigma ini adalah landasan pembelajaran yang berbasis pada paradigma student centered learning.

Upaya untuk merealisasikan pembelajaran berbasis student centered learning tersurat dalam salah satu prinsip pengembangan Kurikulum, 
bahwa kurikulum harus berpusat pada potensi peserta didik. Hal ini merupakan indikasi bahwa pembelajaran berbasis paradigma student centered learning harus dikembangkan di sekolah.

Kenyataannya, tidak mudah melaksanakan berbagai langkah yang dapat menunjang harapan tersebut. Hal ini dapat dilihat dari berbagai permasalahan kurang berkualitasnya proses pembelajaran dan rendahnya hasil belajar siswa. Hasil surve selama 3 tahun sejak Th 2003-2005 di Bali, Palangkaraya, Malang, Surabaya, dan Aceh telah mengungkapkan bahwa pembelajaran yang dilakukan oleh para guru SMA masih menunjukkan lebih berpusat pada guru (Ardhana et al, 2003; Ardhana et al, 2004; dan Ardhana et al, 2005). Hasil surve Natajaya et al (2008) dan Santyasa et al (2009) di Provinsi Bali menemukan bahwa ada kecenderungan pembelajaran masih berpusat pada guru. Santyasa dan Suwindra 2008) mengungkapkan bahwa pembelajaran di SMA sering dilakukan dengan cara guru menjelaskan, siswa mendengarkan dan mencatat. Praktikpraktik pembelajaran yang cenderung berpusat pada guru tersebut berpotensi menghambat pengembangan kebiasaan beroikir dan bertindak bagi siswa.

Menurut Tim Broad-Based Education, kebiasaan berpikir dan bertindak merupakan salah satu tujuan yang harus dicapai dalam proses belajar siswa di sekolah. Dalam dimensi belajar (Marzano et al (1993), kebiasaan berpikir dan bertindak merupakan dimensi puncak dalam proses belajar siswa. Menurut Krulik dan Rudnik (1996), kebiasaan berpikir dan bertindak digambarkan secara hirarkhis mulai dari retention, basic, critical, dan crative thinking.

Dimensi berpikir tersebut sangat menantang pembelajaran di sekolah. Menurut American Association for the Advancement of Science (AAAS)(1994) dan National Research Council (NRC)(1996) dalam (Barak \& Shakhman, 2008), bahwa tujuan pendidikan adalah reasoning and character development. Untuk mencapai tujuan tersebut, mereka menganjurkan bahwa pembelajaran yang lebih tepat adalah yang cenderung mengembalikan siswa ke fitranya sebagai manusia. Schrow et al (dalam Barak \& Shakhman, 2008) menegaskan bahwa dalam pembelajaran hendaknya lebih memberdayakan potensi diri peserta didik. Oleh sebab itu, pemberdayan model-model pembelajaran berpusat pada siswa (Student Centered Learning/SCL) adalah sebuah keniscayaan yang harus dilakukan dalam praksis pendidikan dalam rangka pencapaian tujuan-tujuan pendidikan secara optimal, khususnya peningkatan penalaran dan karakter siswa di sekolah.

Berdasarkan latar belakang masalah di atas, tujuan penelitian ini adalah mendeskripsikan 6 (enam) hal sebagai berikut. (1) Tanggapan para kepala sekolah tentang pentingnya pengembangan model-model studentcenteterd learning (SCL). Pengalaman-penglaman kepala sekolah dalam melakukan pembinaan kepada para guru dalam pengembangan modelmodel SCL. (3) Tanggapan para guru tentang pentingnya pengembangan model-model SCL. (4) Pengalaman guru dalam mengimplementasikan modelmodel SCL. (5) Penalaran (reasoning) 
siswa SMA, yang mencakup kemampuan berpikir dasar, kemampuan berpikir kritis, dan kemampuan berpikir kreatif. (6) Kualitas karakter siswa SMA? Pencapaian tujuan tersebut sangat penting untuk mengungkap kebutuhan akan pengembangan modelmodel SCL. Model-model tersebut penting untuk dikembangkan sebagai fasilitas belajar bagi siswa untuk melakukan olah pikir secara optimal. Olah pikir yang mampu dilakukan oleh siswa sangat membantu mereka dalam menginternalisasi konsep-konsep baru yang dipelajarinya berbasis pada pengetahuan yang telah dimiliki. Pengintegrasian pengetahuan baru ke pengetahuan yang telah dimiliki (pengetahuan awal) siswa dapat berlangsung melalui proses-proses pembelajaran yang berpusat pada siswa, antara lain proses-proses conceptual change (Baser, 2006; Barak \& Shakhman, 2008; Santyasa, 2004; Taber, 2011), problem-based learning (Bigelow, 2004; Boud, \& Feletti, 1997; Wood, 2004), project-based learning (AlAtabi \& Chin, 2007; Egenrieder, 2007; Ellis, \& Hafner, 2008; Foss et al, 2007), group investigation (Okur Akcay \& Doymus, 2012; Santyasa \& Suwindra, 2008), nature of science oriented learning (Metin, 2012; Wenning, 2006), self-regulated learning (Caliscan \& Seicuk, 2010; Cheng, 2011), dan proses-proses lainnya. Oleh sebab itu, pengemasan pembelajaran seyogyanya diarahkan pada pengembangan modelmodel SCL.

\section{METODE}

Penelitian "pengembangan model-model SCL untuk meningkatkan penalaran dan karakter siswa SMA" ini menggunakan desain Research and Development (R\&D)(Borg \& Gall, 2004) sebagai grant design.

Penelitian ini lebih memusatkan perhatian pada analisis kebutuhan (need assessment) tentang pentingnya pengembangan model-model SCL. Analisis kebutuhan dilakukan melalui eksplorasi data keberadaan modelmodel SCL, Rencana Pelaksanaan Pembelajaran (RPP), Lembaran Kerja Siswa (LKS), asesmen proses dan produk pembelajaran, persepsi dan harapan kepala sekolah dan guru terhadap upaya pengembangan modelmodel SCL, data tentang penalaran, dan data tentang karakter siswa SMA.

Subjek penelitian ini adalah siswa SMA, guru-guru SMA (Berikut produk-produk RPP, LKS, dan asesmen yang digunakan), dan Kepala SMA di kabupaten/kota di Bali. Pengambilan sampel penelitian ditetapkan dengan teknik stratified random sampling. Sampel guru dan kepala SMA diambil dari 9 (sembilan) kabupaten/kota di Provinsi Bali. Masing-masing kabupaten/kota melibatkan 3 (tiga) sekolah, sehingga terdapat 27 kepala sekolah yang terlibat dalam penelitian. Berdasarkan lokasi sekolah, ditetapkan 1 (satu) SMA di pusat kota, 1 (satu) SMA di pinggiran kota, dan 1 (satu) SMA di pedesaan. Pada masing-masing sekolah ditetapkan 2 orang guru sebagai sampel penelitian, sehingga jumlah guru yang terlibat adalah sebanyak 54 orang.

Objek penelitian ini adalah model-model SCL dan perangkatperangkatnya yang ada dan digunakan oleh para guru di Provinsi Bali. Objek perangkat-perangkat pembelajaran yang dikaji mencakup 3 (tiga) dimensi, yaitu 
(1) Rencana Pelaksanaan Pembelajaran (RPP), (2) Lembaran Kerja Siswa (LKS), dan (3) asesmen pembelajaran. Di samping itu, diteliti pula persepsi dan harapan-harapan kepala sekolah dan guru terhadap model-model SCL, penalaran, dan karakter siswa.

Instrumen yang digunakan untuk mengumpulkan data, adalah pedoman wawancara untuk kepala sekolah, angket untuk guru, pedoman pengamatan model-model-model pembelajaran yang digunakan selama ini, tes untuk penalaran siswa, dan angket karakter siswa. Untuk menganalisis data penelitian, digunakan teknik analisis deskriptif.

\section{HASIL}

Dalam analisis kebutuhan ini, telah diwawancarai 27 kepala sekolah, telah disebarkan angkat kepada 54 guru, telah diamati 54 RPP dan LKS serta model asesmen yang digunakan oleh guru dalam pembelajaran, telah disebarkan tes dan angket pada 362 siswa SMA.

pada kepala sekolah, dapat dideskripsikan bahwa kepala sekolah cenderung belum pernah melakukan pembinaan secara khusus dalam pengembangan model-mdel pembelajaran yang berpusat pada siswa. Minimnya pembinaan yang dilakukan oleh kepala sekolah tersebut disebabkan karena pemahaman kepala sekolah tentang model-model pembelajaran yang kurang memadai. Oleh karena itu, 100\% kepala sekolah menyatakan sangat mengharapkan adanya upaya penelitian pengembangan pembelajaran berpusat pada siswa
(SCL) dan 100\% kepala sekolah menyatakan akan memberikan kesempatan dan dukungan bagi para guru untuk mengikuti program pelatihan pengembangan model-model pembelajaran berpusat pada siswa (SCL).

Hasil analisis data respon guru menunjukkan bahwa model-model pembelajaran yang cerderung diterapkan oleh para guru dalam pembelajaran adalah kurang memberdayakan potensi diri peserta didik. Model-model pembelajaran tersebut adalah (1) model pemberian informasi oleh guru kepada siswa, (2) model ceramah klasikal, (3) model ceramah diikuti tanya jawab, (4) model pemberian tugas rumah, (5) model demonstrasi oleh guru, (6) model penugasan siswa untuk eksperimen berdasarkan contoh guru, dan (7) model simulasi komputer yang didemonstrasikan oleh guru. SCL yang pernah diterapkan oleh sebagian kecil guru hanya pembelajaran kooperatif, namun kebanyakan dari mereka hanya mencoba model student-team achievement division (STAD). Di samping pembelajaran koopeatif, terdapat pula sejumlah kecil guru telah menerapkan problem-based learning (PBL), sedangkan model-model SCL yang lain, seperti model perubahan konseptual, project-based learning $(\mathrm{PjBL})$, pembelajaran berorientasi nature of science (NOS), model self-regulated learning (SRL), outdoor learning, pembelajaran berbasis lingkungan, memang belum diterapkan secara optimal. Alasan guru tidak menggunakan model SCL dalam pembelajaran, karena mereka belum banyak memahami model-model 
tersebut. Oleh sebab itu, guru yang menyatakan bahwa mereka sangat perlu dan mengharapkan adanya upaya pengembangan model-model SCL, mereka memandang sangat perlu upaya itu dilakukan, mereka mendukung upaya pengembangan dan mereka akan menyiapkan diri untuk terlibat dalam proses pengembangan dan implementasi produk SCL.
Penalaran siswa yang mencakup (a) keterampilan berpikir dasar direspon oleh 228 siswa, (b) keterampilan berpikir kritis direspon oleh 227 siswa, dan (c) keterampilan berpikir kreatif direspon oleeh 191 siswa, yang berhasil dianalisis dalam penelitian ini disajikan pada Tabel 01.

Tabel 01 Penalaran Siswa SMA di Provinsi Bali (Skala 100)

\begin{tabular}{|c|l|c|c|l|}
\hline No & \multicolumn{1}{|c|}{ Dimensi Berpikir Sains } & M & \multicolumn{1}{c|}{ SD } & \multicolumn{1}{c|}{ Kategori } \\
\hline 1 & Keterampilan berpikir dasar sains & 43,35 & 5,33 & Kurang \\
\hline 2 & Keterampilan berpikir kritis sains & 44,30 & 8,57 & Kurang \\
\hline 3 & Keterampilan berpikir kreatif sains & 34,88 & 8,94 & Sangat kurang \\
\hline 4 & Penalaran siswa & 40,51 & 7,58 & Kurang \\
\hline
\end{tabular}

Pada Tabel 01, tampak bahwa penalaran siswa SMA di Provinsi Bali dengan nilai rata-rata $M=40,51$ dengan simpangan baku SD $=7,58$. Pada pedoman konversi nilai absolut skala lima, nilai rata-rata penalaran siswa tersebut berada pada rentangan 40,054,9 dengan kategori kurang.

Karakter siswa SMA di Provinsi Bali yang dianalisis dalam penelitian ini disajikan pada Tabel 02.

Tabel 02 Peluang kepemilikan karakter bangsa bagi siswa SMA di Provinsi Bali ( $\mathrm{N}=362$ orang)

\begin{tabular}{|c|c|c|c|c|c|c|c|c|c|c|c|c|}
\hline \multirow[t]{2}{*}{$\begin{array}{l}\mathrm{N} \\
\mathrm{O}\end{array}$} & \multirow[t]{2}{*}{$\begin{array}{l}\text { Kategori } \\
\text { Karakter }\end{array}$} & \multicolumn{10}{|c|}{$\begin{array}{l}\text { Persentase jumlah responden yang memilih setiap butir } \\
\text { karakter bangsa (\%) }\end{array}$} & \multirow{2}{*}{$\begin{array}{c}\% \\
\text { Rata- } \\
\text { rata }\end{array}$} \\
\hline & & 1 & 2 & 3 & 4 & 5 & 6 & 7 & 8 & 9 & 10 & \\
\hline 1 & $\begin{array}{l}\text { Sangat } \\
\text { baik }\end{array}$ & 60,08 & 56,36 & 20,17 & 0,00 & 22,10 & 33,98 & 56,63 & 73,76 & 41,16 & 59,39 & 42,36 \\
\hline 2 & Baik & 29,76 & 0,00 & 41,85 & 37,15 & 40,09 & 0,00 & 3,59 & 0,00 & 0,00 & 3,59 & 15,60 \\
\hline 3 & $\begin{array}{l}\text { Cukup } \\
\text { baik }\end{array}$ & 0,00 & 0,28 & 0,00 & 0,00 & 0,00 & 53,59 & 0,00 & 0,00 & 0,00 & 0,00 & 5,39 \\
\hline 4 & $\begin{array}{l}\text { Kurang } \\
\text { baik }\end{array}$ & 14,64 & 19,06 & 0,00 & 5,68 & 6,31 & 3,18 & 21,13 & 2,95 & 29,28 & 34,62 & 13,69 \\
\hline 5 & $\begin{array}{l}\text { Tidak } \\
\text { baik }\end{array}$ & 0,00 & 10,50 & 9,40 & 4,79 & 0,50 & 0,00 & 13,20 & 0,00 & 2,49 & 4,70 & 4,56 \\
\hline 6 & $\begin{array}{l}\text { Sangat } \\
\text { tidak } \\
\text { Baik }\end{array}$ & 0,00 & 9,67 & 000 & 0,00 & 0,00 & 0,00 & 0,00 & 0,00 & 0,00 & 0,00 & 0,97 \\
\hline
\end{tabular}

Tabel 02 menunjukkan persepsi siswa atas interaksinya dengan pembelajaran, yang sekaligus merepresentasikan karakter bangsa, menunjukkan bahwa 42,36\% siswa berpeluang memiliki karakter sangat baik, 15,60\% siswa berpeluang memiliki karakter baik, 5,39\% siswa berpeluang 
memiliki karakter cukup baik, 13,69\% siswa berpeluang memiliki karakter kurang baik, 4,56\% siswa berpeluang memiliki karakter tidak baik, dan 0,97\% siswa berpeluang memiliki karakter sangat tidak baik. Jumlah siswa yang karakternya harus dikembangkan ke arah yang lebih baik adalah sebanyak $40,21 \%$.

\section{PEMBAHASAN}

Seperti yang tersirat dalam UU Sisdiknas No 20 Tahun 2003, bahwa Pendidikan Nasional berfungsi mengembangkan penalaran dan karakter siswa.

Penalaran dan karakter siswa adalah 2 (dua) variabel yang diperoleh dari respon siswa yang menjadi bagian penting dalam analisis kebutuhan dalam rangka pengembangan model-model student-centered learning (SCL) dalam penelitian ini.

Hasil penelitian yang

mengungkap 10 (sepuluh) pilar karakter bangsa (Suyanto, 2010), yang direspon oleh 362 siswa SMA, menunjukkan bahwa 42,36\% siswa berpeluang memiliki karakter sangat baik, 15,60\% siswa berpeluang memiliki karakter baik, $5.39 \%$ siswa berpeluang memiliki karakter cukup baik, 13,69\% siswa berpeluang memiliki karakter kurang baik, 4,56\% siswa berpeluang memiliki karakter tidak baik, dan 0,97\% siswa berpeluang memiliki karakter sangat tidak baik. Jumlah siswa yang karakternya harus dikembangkan ke arah yang lebih baik adalah 40,21\%.

Upaya pengembangan karakter bangsa pada peserta didik dapat dilakukan dengan cara menyelenggarakan pendidikan karakter terintegrasi pada semua bidang studi.
Hal ini sangat penting, karena karakter mencerminkan kebajikan seseorang. Hal ini senada dengan pendapat (Lickona, 1999), bahwa pendidikan karakter penting diselenggarakan sebagai upaya pengembangan kebajikan. Hal senada juga diungkapkan oleh Yahya Khan (2010:1) dan Raka et al (2011:xi), bahwa pendidikan karakter penting dilaksanakan agar setiap siswa mampu mengembngkan kebajikan.

Pengembangan kebajikan peserta didik dapat bersumber dari orang lain melalui keteladanan yang antara lain dapat dilakukan melalui pembelajaran pemberdayaan potensi diri siswa. Oleh sebab itu, dibutuhkan model-model pembelajaran yang mampu membudayakan dan memberdayakan siswa, sehingga pendidikan menjadi suatu proses pembudayaan dan pemberdayaan peserta didik (Bab III Pasal 4 Ayat 4 UU Sisdiknas Tahun 2003). Jadi, modelmodel pembelajaran yang mampu memberdayakan potensi peserta didik sangat penting untuk dikembangkan dalam rangka membangun karakter peserta didik.

Kebajikan peserta didik yang diperoleh dari potensi dirinya dapat berasal dari pengetahuan dan penalaran yang telah dimiliki atau yang sedang berkembang. Hasil penelusuran penalaran peserta didik pada skala 100 (skor tertinggi 100 dan terendah 0) menunjukan bahwa, nilai rata-rata $\mathrm{M}=$ 40,51 dengan simpangan baku $S D=$ 7,58. Pada pedoman konversi nilai absolut skala lima, nilai rata-rata penalaran siswa tersebut berada pada rentangan 40,0-54,9 dengan kategori kurang. Rendahnya penalaran siswa tersebut diduga karena pembelajaran di 
sekolah belum memberdayakan potensi diri peserta didik secara optimal. Dugaan ini didukung oleh hasil analisis respon 54 orang guru terhadap angket yang disebarkan, bahwa model-model pembelajaran yang diterapkan oleh guru dalam pembelajaran adalah kurang memberdayakan potensi diri peserta didik.

Penelitian ini mengungkapkan bahwa pembelajaran berpusat pada guru cenderung mendominasi di sekolah. Hal ini disebabkan karena guru masih memiliki pandangan bahwa "model pembelajaran tidak penting, yang lebih penting adalah penguasan materi pelajaran". Respon yang lain, bahwa "model pembelajaran hanya teori, prakteknya tidak ada". Penelusuran lebih lanjut mengungkapkan bahwa respon-respon yang bersifat antithesis tersebut disebabkan semata-mata karena mereka (para guru) belum memahami secara komprehensif tentang modelmodel pembelajaran, lebih-lebih yang mampu memberdayakan potensi peserta didik, yang sering disebut dengan student-centered learning (SCL). SCL yang pernah diterapkan oleh sebagian kecil guru hanya pembelajaran kooperatif, namun kebanyakan dari mereka hanya mencoba model student-team achievement division (STAD), sedangkan model group investigation sangat sedikit guru mencobanya. Di samping pembelajaran koopeatif, terdapat pula sejumlah kecil guru telah menerapkan problem-based learning (PBL), sedangkan model-model SCL yang lain, seperti model perubahan konseptual, project-based learning $(\mathrm{PjBL})$, pembelajaran berorientasi NOS, model self-regulated learning (SRL), outdoor learning, pembelajaran berbasis lingkungan, memang belum diterapkan secara optimal. Hal ini memperkuat dugaan, bahwa guru-guru belum banyak mengenal, memahami, dan menerapkan model-model SCL dalam pembelajaran. Fakta yang memperkuat hal ini, adalah adanya respon guru yang menyatakan bahwa mereka sangat mengharapkan adanya upaya pengembangan modelmodel SCL, mereka memandang sangat perlu upaya itu dilakukan, mereka mendukung upaya pengembangan dan mereka akan menyiapkan diri untuk terlibat dalam proses pengembangan dan implementasi produk SCL. Alasan mereka, bahwa agar lebih mendalami tentang model-model SCL, baik teori maupun prakteknya.

Hasil pengamatan terhadap produk rencana dan pelaksanaan pembelajaran (RPP), lembaran kerja siswa (LKS), dan model penilaian yang dikembangkan oleh para guru, membuktikan bahwa guru-guru belum secara optimal mengenal, memahami, dan menerapkan model-model SCL dalam pembelajaran. Hasil pengamatan tersebut menunjukkan bahwa terdapat sejumlah RPP yang tidak mencantumkan model pembelajaran yang diterapkan. Terdapat sejumlah LKS yang tidak jelas arah sasaran yang dituju dan cenderung mengarah ke pembelajaran tradisional. Penilaian yang ditemukan pada sejumlah RPP cenderung mengases lebih banyak hasil belajar, tidak mencantumkan rubrik penilaian, tidak mencantumkan tes yang digunakan untuk mengukur pencapaian indikator, dan yang menarik adalah adanya sejumlah RPP yang tidak mencantumkan asesmen. 
Salah satu faktor yang sangat kuat berpengaruh terhadap rendahnya pemahaman dan kemampuan guru menerapkan model-model SCL dalam pembelajaran, adalah belum adanya upaya-upaya kepala sekolah untuk melakukan pembinaan secara khusus. Hal ini terungkap dari hasil wawancara terhadap 27 orang kepala sekolah di Provinsi Bali. Mereka menyatakan bahwa, pembinaan pengembangan profesionalisme guru, terutama yang berkaitan dengan kompetensi pedagogi hanya dilakukan secara umum melalui rapat-rapat rutin. Kepala sekolah cenderung mengandalkan pembinaan yang dilakukan melalui MGMP, dari dinas kabupaten setempat, atau dari universitas. Hal ini tentunya tidak memberikan pengaruh yang optimal dalam pengembangan kompetensi guru, khususnya dalam mengenal, memahami, dan menerapkan modelmodel SCL, yang sangat mendukung kompetensi guru bidang pedagogi. Seyogyanya, kepala sekolah secara rutin melakukan pembinaan profesionalisme guru menyangkut keempat kompetensi yang diwajibkan oleh pemerintah. Hal ini sesuai dengan amanat UU No 14 Tahun 2005 tentang Guru dan Dosen, Bab IV Pasal 34 Ayat 2 menegaskan bahwa satuan pendidikan yang diselenggarakan oleh masyarakat wajib membina dan mengembangkan kualifikasi akademik dan kompetensi guru. Pembinaan kompetensi guru hendaknya disesuaikan dengan amanat Bab IV Pasal 32, UU Guru dan Dosen, yang ayat-ayatnya menyatakan sebagai berikut. (1) Pembinaan dan pengembangan guru meliputi pembinaan dan pengembangan profesi dan karier. (2) Pembinaan dan pengembangan profesi guru sebagaimana dimaksud pada ayat (1) meliputi kompetensi pedagogik, kompetensi kepribadian, kompetensi sosial, dan kompetensi professional. (3) Pembinaan dan pengembangan profesi guru sebagaimana dimaksud pada ayat (1) dilakukan melalui jabatan fungsional. (4) Pembinaan dan pengembangan karier guru sebagaimana dimaksud pada ayat (1) meliputi penugasan, kenaikan pangkat, dan promosi.

$$
\text { Pembahasan terhadap }
$$

pentingnya pembinaan untuk peningkatan kompetensi guru tersebut mengindikasikan bahwa pengembangan model-model SCL sangat strategis untuk segera dilakukan. Dua hal penting yang dapat dipetik dari pengembangan model-model SCL tersebut, adalah (1) proses pengembangan SCL akan melibatkan guru-guru yang akan memberikan peluang kepada mereka untuk memahami dan melakukan ulang proses tersebut dalam pembelajaran sehari-hari, sehingga mereka menjadi guru yang belajar sepanjang hayat, (2) produk pengembangan SCL akan memberikan model yang dapat menginspirasi guru-guru yang belum berani mencoba ulang proses pengembangan untuk menerapkan langsung, dan kepala sekolah untuk memahami pentingnya pembinaan secara spesifik model-model SCL, sehingga dapat mewujudkan proses dan produk pembelajaran yang sesuai dengan standar nasional. Standar nasional terdapat dalam Peraturan Pemerintah Republik Indonesia (PPRI) No 19 Tahun 2005, tentang Standar Nasional Pemdidikan (SNP), Bab IV Pasal 19, yang ayat-ayatnya 
menyatakan sebagai berikut. (1) Proses pembelajaran pada satuan pendidikan diselenggarakan secara interaktif, inspiratif, menyenangkan, menantang, memotivasi peserta didik untuk berpartisipasi aktif, serta memberikan ruang yang cukup bagi prakarsa, kreativitas, dan kemandirian sesuai dengan bakat, minat, dan perkembangan fisik serta psikologis peserta didik. (2) Selain ketentuan sebagaimana dimaksud pada ayat (1), dalam proses pembelajaran pendidik memberikan keteladanan. (3) Setiap satuan pendidikan melakukan perencanaan dan pelaksanaan proses pembelajaran, penilaian hasil pembelajaran, dan pengawasan proses pembelajaran untuk terlaksananya proses pembelajaran yang efektif dan efisien.

Standar pembelajaran seperti yang diamanatkan oleh PPRI tersebut dapat diakomodasi oleh model-model SCL. Jika model-model SCL dapat dikembangkan secara optimal, maka penerapannya dalam pembelajaran akan dapat meningkatkan penalaran. Hal ini disebabkan karena model-model SCL secara total memberdayakan potensi peserta didik untuk mengembangkan kemampuankemampuan berpikir mencakup dimensi basic thinking critical thinking, dan creative thinking. Ketiga dimensi berpikir tersebut, menurut Krulik \& Rudnick (1996) disebut penalaran (reasoning). Marzano et al (1988) menyatakan bahwa, pembelajaran yang memberdayakan potensi peserta didik dipastikan dapat meningkatkan kemampuan-kemampuan berpikir mereka, tidak hanya pada level rendah, tetapi juga mencapai kemampuan berpikir tingkat tinggi, mencakup penalaran.

Penerapan model-model SCL dalam peembelajaran tidak hanya mampu meningkatkan penalaran, tetapi juga meningkatkan karakter siswa. Hal ini sesuai dengan pendapat Marzano et al (1988), bahwa pembelajaran yang lebih memberdayakan potensi peserta didik akan dapat mengembangkan dimensi belajar siswa, tidak hanya menyangkut intelektual, tetapi juga sikap dan nilai, kebiasaan berpikir positif, dan moral yang baik bagi siswa. Bahkan secara lebih spesifik dan tegas, Lickona (1999) menyakan bahwa penerapan SCL dalam pembelajaran dapat meningkatkan karakter siswa menuju ke arah yang lebih baik.

Berdasarkan hasil pembahasan di atas, pengembangan model-model SCL untuk meningkatkan penalaran dan karakter siswa adalah suatu keniscayaan untuk diwujudkan. Hal ini didukung oleh 54 guru-guru dan 27 kepala sekolah, yang secara tegas menyatakan bahwa, pengembangan model-model SCL adalah sangat penting untuk segera diwujudkan.

Proposisi-proposisi yang dapat diformulaikan dari hasil penelitian ini adalah sebagai berikut. (1) Model-model SCL adalah bagian yang sangat penting untuk efesiensi dan efektivitas praksis pendidikan. Implikasinya, SCL seyogyanya selalu dijadikan objek kajian bidang pedagogi dalam upaya meningkatkan produktivitas pendidikan. (2) Pemberdayaan potensi diri secara total merupakan unsur terpenting dalam belajar. Implikasinya, bahwa proses belajar mesti didukung oleh modelmodel SCL. Oleh sebab itu, modelmodel SCL wajib dipahami dan 
diimplementasikan oleh guru dalam praksis pendidikan. (3) Pembinaan profesionalisme guru menjadi bagian penting dalam upaya meningkatkan kompetensi guru. Implikasinya, bahwa satuan pendidikan, mulai dari sekolah hingga perguruan tinggi memiliki kewajiban untuk melakukan pembinaan secara kontinyu untuk mengembangkan keempat kompetensi guru, seperti yang diamanatkan oleh undang-undang. (4) SCL merupakan unsur penting dalam pengembangan penalaran dan karakter siswa di sekolah. Implikasinya, sangat perlu memberikan otonomi secara luas kepada guru untuk menerapkan SCL dan model-model asesmen yang sesuai dengan upaya pengembangan penalaran dan karakter siswa di sekolah.

\section{SIMPULAN}

Berdasarkan hasil penelitian dan pembahasan yang telah diungkapkan pada bagian sebelumnya, diajukan simpulan-simpulan penelitian sebagai berikut. (1) Para kepala sekolah merespon sangat penting adanya pengembangan model-model studentcentered learning (SCL). (2) Kepala sekolah belum pernah melakukan pembinaan secara khusus kepada guru dalam pengembangan model-model SCL. (3) Model-model SCL belum ditemukan keberadaannya dalam praksis pendidikan. (4) Para guru belum memiliki pengalaman yang memadai dalam mengimplementasikan modelmodel SCL. Pembelajaran dan penilaian pembelajaran yang dilakukan selama ini lebih berorientasi pada produk dibandingkan proses. (5) Penalaran (reasoning) siswa SMA di Provinsi Bali yang mencakup keterampilan berpikir dasar direspon oleh 228 siswa, keterampilan berpikir kritis direspon oleh 227 siswa, dan keterampilan berpikir kreatif direspon oleh 191 siswa, adalah terkategori kurang. (6) secara deskriptif, peluang kepemilikan karakter bangsa bagi siswa, yang diungkap dari 362 siswa SMA, menunjukkan bahwa $42,36 \%$ siswa berpeluang memiliki karakter sangat baik, sedangkan yang berkategori baik, cukup baik, kurang baik, tidak baik, dan sangat tidak baik adalah 40,21\%.

\section{SARAN-SARAN}

Penelitian ini telah mengungkap bahwa, belum adanya upaya-upaya guru, kepala sekolah, dan sekolah untuk melakukan pengembangan modelmodel SCL. Model-model SCL tersebut keberadaannya sangat langka bahkan belum ditemukan dalam praksis pendidikan. Oleh sebab itu, diajukan saran-saran sebagai berikut. (1) Kepada pemerintah disarankan agar melakukan koordinasi dan sekaligus memberikan dukungan kepada sekolah untuk mengembangkan model-model SCL. (2) Kepada para kepala sekolah khususnya kepala SMA di Provinsi Bali, dianjurkan agar sering melakukan pembinaan pengembangan profesionalisme guru, mencakup pengembangan kompetensi pedagogi, profesional, personal, dan sosial. Salah satu cara yang dapat dilakukan, khususnya pembinaan kepada guru-guru SMA, adalah upaya pengembangan model-model SCL. (3) Disarankan kepada guru SMA di Provinsi Bali, agar selalu respektif terhadap upaya-upaya inovatif, baik yang mampu dilakukan sendiri, maupun menyertakan keterlibatannya dalam berbagai kegiatan yang mendukung 
pengembangan profesionalisme guru. Salah satu tindak respektif dan inovatif, adalah komitmen untuk lebih banyak melibatkan diri dalam upaya-upaya pengembangan model-model SCL. Guru juga dianjurkan agar memiliki keinginan dan komitmen yang tinggi dalam menerapkan gagasan-gagasan inovatif, seperti penerapan model-model SCL dalam pembelajaran di sekolah. Untuk mendukung keinginan dan komitmen tersebut, para guru hendaknya menyediakan waktu dan tenaga dalam meningkatkan keterlibatannya dalam proses pembinaan, baik yang dilakukan oleh sekolah maupun oleh pihak perguruan tinggi, khususnya LPTK yang handal di bidang itu.

\section{DAFTAR PUSTAKA}

Al-Atabi, M. \& Chin, S. B. 2007. A case study in project based learning using flow visualization. Journal of Engineering Science and Techno-logy. 2(3). 290-297.

Ardhana, W., Kaluge, L., \& Purwanto. 2003. Pembelajaran inovatif untuk pemahaman dalam belajar matematika dan sains di SD, SLTP, dan di SMU. Laporan penelitian. Penelitian Hibah Pasca Angkatan I tahun I. Direktoral Penelitian dan Pengabdian Pada Masyarakat. Ditjen Dikti. Depdiknas.

Ardhana, W., Kaluge, L., \& Purwanto. 2004. Pembelajaran inovatif untuk pemahaman dalam belajar matematika dan sains di SD, SLTP, dan di SMU. Laporan penelitian. Penelitian Hibah Pasca Angkatan I tahun II. Direktoral Penelitian dan
Pengabdian Pada Masyarakat. Ditjen Dikti. Depdiknas.

Ardhana, W., Kaluge, L., \& Purwanto. 2005. Pembelajaran inovatif untuk pemahaman dalam belajar matematika dan sains di SD, SLTP, dan di SMU. Laporan penelitian. Penelitian Hibah Pasca Angkatan I tahun III. Direktoral Penelitian dan Pengabdian Pada Masyarakat. Ditjen Dikti. Depdiknas.

Barak, M., \& Shakhman, L. 2008. Reform-based science teaching: Teachers' instructional practices and conceptions. Eurasia Journal of Mathematics, Science \& Technology Eduvation. 4(1). 11-20.

http://www.ejmste.com/v4n1/ eurasia v4n1 Barak.pdf.

Baser, M. 2006. Effect of conceptual change oriented instruction on students' understanding of heat and temperature concepts. Journal of Maltese Education Research. 4(1). 64-79. http://www.educ.um.edu.mt/imer

Caliscan, S. \& Seicuk, G. S. 2010. Preservice teachers' use of self regulation strategies in phyisics problem solving: Effects of gender and academic achievement. International Journal of The Physical Sciences. 5(12). 1926-1938.

Cheng, E. C. K. 2011. The role of self regulated learning in enhancing learning performance. The International Journal of Research and Review. 6(1). 1-15. 
Depdiknas. 2006. Kurikulum sekolah tetap mengacu pada BSNP, penerapan KTSP tahun 2009/2010. http://www. ekebumen.net.

Egenrieder, J. A. 2007. Communityfocus, project based learning to promote diversity in STEM. Journal of Virginia Science Education. 1(2). 5-16.

Ellis, T. J. \& Hafner, W. 2008. Building a framework to support project based collaborative learning experiences in an asynchronous learning network. Interdisciplinary Journal of ELearning and Learning Object. 4. 167-190.

Foss, P., Carney, N., McDonald, K., \& Rooks, M. 2007. Project-Based Learning Activities for ShortTerm Intensive English Programs. Professional Teaching Articles. 23. http://www.asian-efljournal.com/pta

Krulik, S., \& Rudnick, J. A. 1996. The new sourcebook for teaching reasoning and problem solving in Junior and Senior High School. Boston: Allyn and Bacon.

Lickona, T. 1999. Character education: The cultivation of virtue. In Regeluth, C. M. (Ed.): Instructional design theories and model: $A$ new paradigm of instructional theory. 591-612. United States of America: Lawrence Erlboum Associates, Inc.
Marzano, R. J., Brandt, R.S., Hughes, C.S., Jones, B.F., Presseisen, B.Z., Rankin, S.C., \& Suhor, C. 1988. Dimensions of thinking: $A$ framework for curriculum and instructon. Alexandria, Virginia: Association for Supervision and Curriculum Development.

Marzano, R. J. 1993. How classroom teachers approach the teaching of thinking. Dalam Donmoyer, R.\& Merryfield, M.M.(Eds): Theory into practice: Teaching for higher order thinking. 32(3). 148-153.

Metin, D. 2012. Effect of a science camp on the children's vews of tentative nature of science. Journal of Studies in Education. 2(1). 164-183. www.macrothink. org/ise.

Natajaya, I N., Santyasa, I W., \& Anggan Suhandana, G. 2008. Pengembangan model pelatihan untuk pembinaan profesi guru dan pengaruhnya terhadap perolehan belajar siswa. Laporan penelitian Hibah Pascasarjana Undiksha. Lembaga Penelitian Undiksha.

Okur Akcay, N. \& Doymus, K. 2012. The effects of group investigation and cooperative learning techniques applied in teaching force and motion subjects on students' academic achievements. Journal of Educational Sciences Research: International EJournal. 2(1). 109-123.

Raka, G., Mulyana, Y., Markam, S. S., Semiawan, C. R., Hasan, S. H., Bastaman, H. D., \& Nuracham, 
N. 2011. Pendidikan karakter di sekolah: Dari gagasan ke tindakan. Jakarta: Elex Media Komputindo.

Santyasa, I W. 2004. Strategi alternatif perubahan konseptual dalam pembelajaran fisika. Wahana matematika dan sains, Jurnal matematika, sains, atau pembelajarannya. No. 2 Th. II, April 2004.

Santyasa, I W., Marhaeni, A. A. I. N., \& Suastra, I W. 2009. Pengembangan perangkat pembelajaran sains SMP bermuatan peta konsep dan model perubahan konseptual serta pengaruhnya terhadap penalaran siswa. Laporan Penelitian Hibah Pascasarjana Tahun 2009. Lembaga Penelitian Undiksha.
Suyanto, 2010. Urgensi pendidikan karakter.

http://waskitamandiribk.wordpres s.com/ 2010/06/02/urgensipendidikan-karakter/

Taber, K. S. 2011. Understanding the nature and processes of conceptual change: An essay review. Educational Review. 14(1). 1-17.

Wenning, C. J. 2006. A pramework for teaching the nature of science. Journal of Physics Teacher Education Online. 3(3). 3-10. http://www.phy.ilstu. edu/ipteo

Yahya Khan, D. 2010. Pendidikan karakter berbasis potensi diri mendongkrak kualitas pendidikan. Yogyakarta: Pelangi. 